\title{
Assessment of Readiness for Industry 4.0 Implementation in Ceramic Industry
}

Tomas Kellner, Martin Necas, Michal Kanak, Martin Kyncl, Jiri Kyncl

Faculty of Mechanical Engineering, Department of Machining, Process Planning and Metrology, CTU in Prague, Technicka 4, 16000 Praha 6. E-mail: tomas.kellner@fs.cvut.cz, m.necas@fs.cvut.cz, michal.kanak@fs.cvut.cz, jiri.kyncl@fs.cvut.cz,martin.kyncl@fs.cvut.cz

This paper focuses on the implementation of principles of Industry 4.0 concept to ceramic industry. The topic of this paper is to address the problematics of the implementation of processes and elements of digitization within the Industry 4.0 concept into ceramic industry. Firstly, thorough literature and bestpractice research will be discussed. Based on the state of current knowledge, concept of the Industry 4.0 Readiness Model for Refractory will be presented. The model's main focus is on the readiness of current business structures, processes and technical and economical situation. It will provide necessary analysis and insight into potential company's processes and background. Based on this analysis, it will be possible to define the main obstacles for future digitalization and automation within Industry 4.0 concept in Refractory industry. On the foundation of data obtained by Industry 4.0 Readiness Model for Refractory, it will be possible to implement the Industry 4.0 solutions with highest added value to specific company, based on its current state. The main purpose of this paper is to summarize and discuss key parameters and framework for Industry 4.0 Readiness Model for Refractory and its connection to future implementation of Industry 4.0 features within ceramic industry.

Keywords: Industry 4.0, Smart Factory, Refractory Industry, Readiness Assessment, Assessment Model

\section{Introduction}

Nowadays elements of production control and manufacturing regulation in the Czech Republic are widespread mainly in traditional segments of industry such as automotive and aviation. Already at the time of Industry 4.0 concept establishment, the technologies of monitoring and regulation of production in automotive and aviation were at a high level. In terms of readiness to implementation of the new elements of Industry 4.0, companies in the automotive and aviation are therefore much better prepared.

The ceramics industry differs from the automotive industry, in particular in the nature of production and the size of the supply chain. Although the ceramic industry is a traditional industry in the Czech Republic, the ideas of the Industry 4.0 concept are not yet well established inside this industry. Given the wide range of products in this industry, this is a complex issue. A more appropriate approach is to address this issue in one segment of the ceramic industry.

The aim of this article is to review current Industry
4.0 models and knowledge of the manufacturing system in the refractory industry, which is considered part of the ceramic industry. With this knowledge, it will be possible to design an Industry 4.0 readiness evaluation model directly for the refractory industry. By focusing on a specific manufacturing process, the model should achieve greater objectivity because of the precise questions concerning the refractory industry. Based on the evaluation model, Industry 4.0 implementation model will be proposed.

\section{Manufacturing system and definition}

This chapter describes the general manufacturing system for refractory products, which is the basis for designing the methodology for the implementation of Industry 4.0 elements. Within the refractory industry, silica and fireclay manufacturing plants have similar production processes. The biggest difference between the production of silica and fireclay is, that silica, unlike fireclay, need to rest before drying. A simplified manufacturing diagram is shown in Fig. 1. The following paragraphs generally describe the manufacturing process.
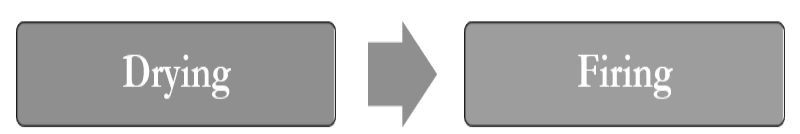

Fig. 1 General scheme of refractory products manufacturing 


\section{- Mixture Preparation}

The process starts with the preparation of the mixture, during which it is necessary to achieve the required structure of selected input raw materials. Unlike conventional ceramics, the resulting chemical composition of the mixture is absolutely essential. It is necessary to weight very accurately. Also, the quality of raw materials is significantly higher than conventional ceramics. For this reason and the reason of lower costs, in most cases the preparation of the mixture is managed by the company itself (grinding and mixture preparation). The first important component of the mixture is an abrasive, which should have a exact shape, size and sharpness. To ensure the stability of these properties, the input mixture is firstly crushed into regular cubic grain using crushers or mills and then sorted by grain size. In association with the preparation of the binder (clays), in most cases it is necessary to dry the binder appropriately before processing, and then to further process it to reach desired structure. Preparation of the mixture is completed by mixing all components in the correct ratio and order using a suitable mixer machine. [1]

\section{- Shaping}

The technology of the forming process is divided according to the type of mixture used (plastics, moldables). While moldables in form of granulates is due to its properties processed only on presses, the mixture of plastics can be pressed at lower pressures, or even manually shaped. The pressed mixture is in both cases full of very hard abrasive materials. That cause rapid wear of metal moulds, because of strong abrasive effects. [2]

\section{- Drying}

Moldables and plastics workpieces are still too wet to be fired after the forming operation. The higher is the water content in the mass, the slower must be the drying process. Drying takes place in tunnel or chamber furnaces, in the case of moldables, often directly on the kiln cars intended for burning furnaces. [2]

- Firing

The last technological operation of the fireclay production process is firing of the dried mixture. Firing takes place in tunnel or chamber furnaces in the temperature range from $1000{ }^{\circ} \mathrm{C}$ to $1500{ }^{\circ} \mathrm{C}$. Transport of products in the furnace is ensured by special kiln cars, which are adapted for easy and quick repairs. During burning, the furnaces must always be occupied with loaded kiln cars in order to avoid significant temperature changes that could cause damage to the furnaces themselves or damage the goods in the kiln. [1][2]

It is only a simplified general manufacturing process in the refractory industry. Different materials and products have different manufacturing process tech- nology. The production of refractory products is relatively demanding compared to the production of classical ceramics. It is necessary to observe all parameters prescribed by the production process (temperature, humidity, drying time). As well as in the production of classical ceramics, refractory production often lacks automation, modern monitoring systems and even sufficient IT structure. Therefore, it is hard to aim for Smart Factory concept without extensive preparations of the production processes and infrastructure. [3] [4]

\section{Current readiness models in Industry 4.0}

There are already several approaches and methodologies to assess the state of digitization, automation and use of Industry 4.0 elements. It is mostly only an assessment of the current situation and does not propose a solution to the situation or future implementation. Assessment models of company readiness to implement Industry 4.0 elements are created mainly by large companies for their own use and commercial activity. For these reasons they are very general. Most models focus more on the energy, automotive and aviation industries. Some companies and their assessment methodologies deal with this issue solely on the basics of advice and consultation, others provide more complex solution with the implementation of Industry 4.0 elements directly to their customers. Fig. 2 shows some models which are used for maturity assess in terms of Industry 4.0 concept.

- PwC, 2017

It is an online self-assessment model for Industry 4.0, developed by PwC, a worldwide consulting company. The model evaluates four phases: digitization, vertical integration, horizontal collaboration and final digitization. It evaluates itself online, identifies the actions needed and compares it with other companies in the industry. [5]

- Rockwell Automation, 2014

Rockwell Automation specialists have designed an evaluation model that assesses the current state and offers a way to implement network operating and information technologies. The model consists of five phases from initial evaluation to final cooperation. [6]

- Isaka, Nagayoshi, Yoshikawa, Yamada, \& Kakeno, 2016

An advanced model for production systems developed by Hitachi. This model classifies production systems in terms of six maturity levels, which gradually lead to increased management efficiency. First-level devices use up-to-date data for visualization. The second level (Connection) achieves traceability. The third level device is used for automatic analysis. The fourth level (measurement) ensures identification and resolution of production barriers. The fifth level means predicting and optimizing production plans and the final 
sixth level is a symbiosis in which resources and production plans are optimized with suppliers. [7]

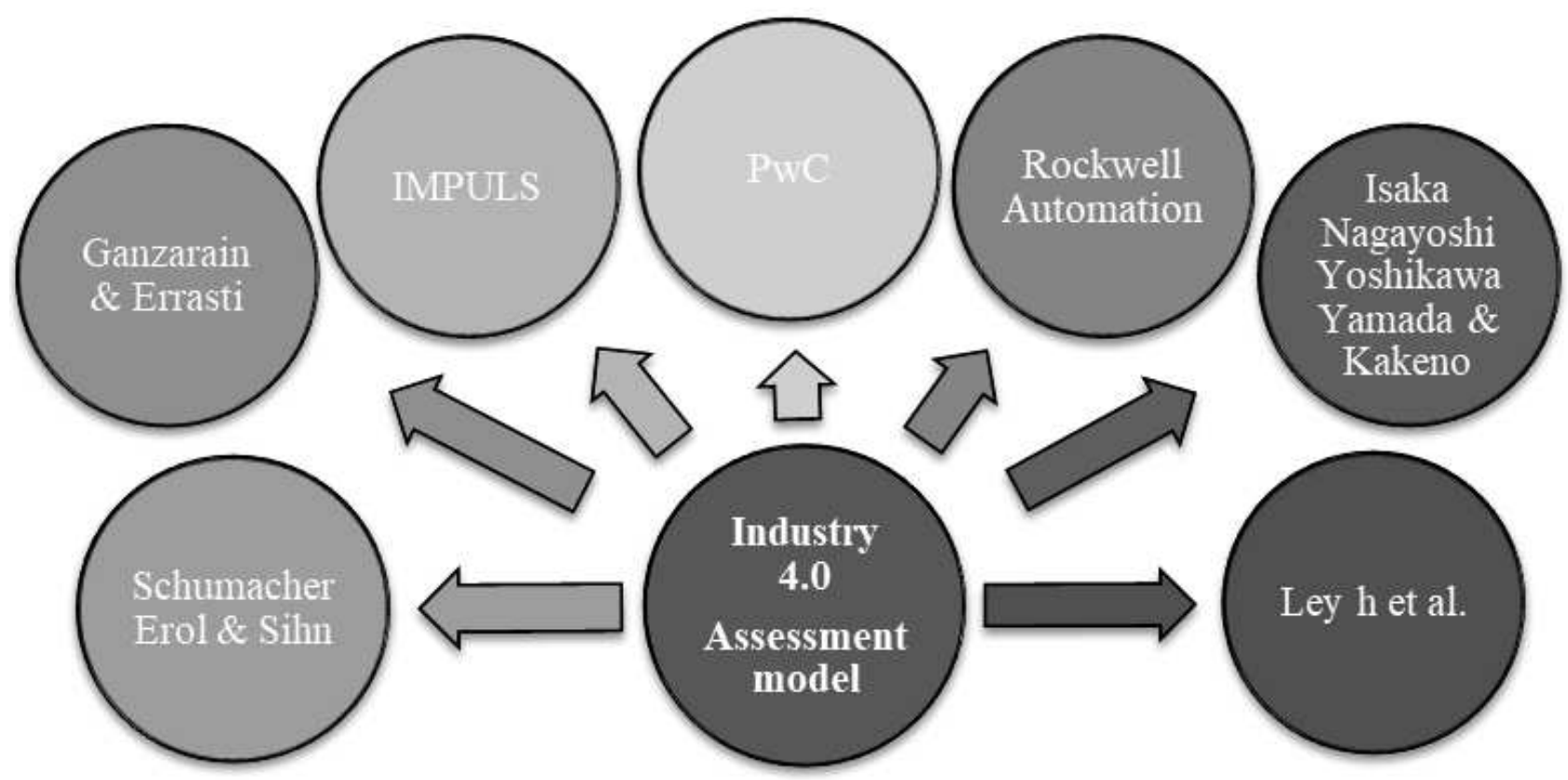

Fig. 2Models for Industry 4.0 maturity assessment

- IMPULS, 2017

IMPULS has developed another self-assessment Industry 4.0 readiness model that addresses technical, organizational and social aspects. Based on these aspects, they evaluate the current state of readiness by assigning them to one of five groups. [8]

- Leyh et al., 2017

This Industry 4.0 integration maturity model has four phases. Vertical integration, horizontal integration, digital product development and cross-cutting technology criteria. The final evaluation divides the companies into five levels. The first stage is the basic level of digitization and it is gradually possible to reach the fifth stage, which is fully optimized digitization. [9]

- Schumacher, Erol, \& Sihn, 2016

The model includes social, technical, and organizational dimensions to assess production readiness for Industry 4.0. The authors of the model have identified a total of nine dimensions, each of which will receive a weighted average value based on the evaluation of various items. It is a complex model with graphs for data visualization and priority identification. This is followed by grading (one to five) according to readiness. [10]

\section{- Ganzarain \& Errasti, 2016}

The model focuses on the process of changing diversification strategies. It is necessary to define a vision, implement a process and implement Industry 4.0 projects and ensure training and risk management. There are five phases from the first, where there are no elements of Industry 4.0 to the highest fifth stage of detailed business plan transformation. [11]

However, none of these models is concerned only with the refractory industry and the individual models are too general or aimed at other industries. This means that a model that deals with the automotive industry in detail will not be very suitable for assessing the readiness of a refractory company. There are many reasons for this, such as the significant difference in the product portfolio, the material of the products, the method of production, the quantity of products produced, the size of the component base, the material storage, but also the current state of both industries. For these and other reasons, these models cannot be used in the manufacturing industry.

\section{Activities within Industry 4.0 in Ceramics industry}

Within the ceramics industry, several pilot models have already been created to help manufacturing companies implement other elements of Industry 4.0. Most of the models were too general or solved only local implementation of individual elements. For this reason, it is not appropriate to use any of the created models.

- Mobile Manufacturing Execution system (MMES)

The main goal of this project was to create a cloudbased MES (Manufacturing Execution System) for mobile devices. By using the cloud, data is available in real time not only to the business itself, but also to suppliers and customers. Mobile technologies do not 
mean high purchase costs and the system is easy to adapt. [4]

- Cloud Laboratory Information Management System (CLIMS)

Similar to the previous model. The cloud storage is also used here. The Cloud storage is here to keep information in electronic form and to easily find information from testing laboratories to check compliance with required standards or customer requirements. [4]

\section{- The Mould Digitalization}

The moulds should be kept for reuse. As a result, the company is losing a significant part of its warehouse capacity. Nowadays there is an effort to have as much data as possible in digital form and to use modern technologies (additive technology). [4]

- Big Data for marketing and internacionalization

Big Data analysis can provide important information that can be used not only to design innovation but also to support trends in the sales sector. [4]

- Scanning of ceramics

Traditional ceramic products (tiles) are fitted with sensors or solar systems to collect digital information. These sensors can be used in the construction of modern so-called smart buildings. [4]

- Monitoring system

An unnamed Portuguese company started placing $\mathrm{QR}$ codes on their final products. Thanks to the QR codes it is possible to obtain accurate information about the manufacturing process of the product (manufacturing method, quality control, batch number, etc.). [4]

- Ceramics Industry 4.0 - maturity model

The maturity model for ceramics industry is still being in development. In Portugal there are involved many universities, companies and the Ceramics Industry Association in that development. The aim of the project is to create a model according to which it will be possible to create solutions for each subsector of the ceramic industry. [4]

Unlike the automotive or aviation industry, the implementation of Industry 4.0 elements in the ceramic industry varies in many factors. There is a big difference in the production profile, storage of input material and finished products, but especially the current state of production automation. Already developed maturity models are individually tailored to the needs of the industry and business, as they are designed in a very general way to serve as a quick tool for subsequent decision-making on the future implementation of Industry 4.0 elements, but all in specific company. So far, no methodology has been described to offer comprehensive solutions for companies of different sizes in the ceramic industry. The following part of the article discusses the suggestion of possible methodologies for the readiness evaluation and the subsequent implementation of Industry 4.0 elements that could be used for refractory industry companies of various sizes.

\section{Design of Industry 4.0 Readiness Model for Refractory}

A key factor in designing a model for assessing the readiness for Industry 4.0 in the refractory industry is its continuity with the future model for the subsequent deployment of elements of Industry 4.0 in the company. The aim of the model is to enable various companies involved in the refractory industry to be able to assess their current preparedness and identify bottlenecks. The right approach to addressing these bottlenecks should then provide the latter model for the implementation of Industry 4.0 elements carried out by using Complex methodical tool, which will be developed in the future and will be closely connected to this Readiness model.

The inspiration for the proposed model was the previous research of general evaluation models for Industry 4.0 which have been verified by several years of functionality. The difference is the specific focus on the refractory industry which has been reflected in the overall structure of the model and the composition of issues that are often directed directly to manufacturing technologies for the manufacture of refractory products. The model is, like most models, divided into 6 separate categories which are evaluated separately (see Fig. 3). The first two categories "company status" and "market status" do not assess preparedness, but merely serve to classify the company in the segment. The reason is a different approach to companies of different sizes. The other 4 categories of "IT and Infrastructure", "Input Materials", "Production Processes" and "Information and Data flows" will be essential to assess the overall preparedness for deployment of Industry 4.0. The weight of the influence of individual categories and their sub-parts will be partly determined by the first two categories, which will provide general information about the company.

\section{- SWOT analysis}

During the design phase of a new project it is essential to create a SWOT analysis with which it is possible to identify threats and market opportunities in a timely manner. SWOT analysis evaluates external and internal features - strengths and weaknesses of the project. The created SWOT analysis for the proposed evaluation and implementation model is shown in Fig. 4 and described in other subchapters. 


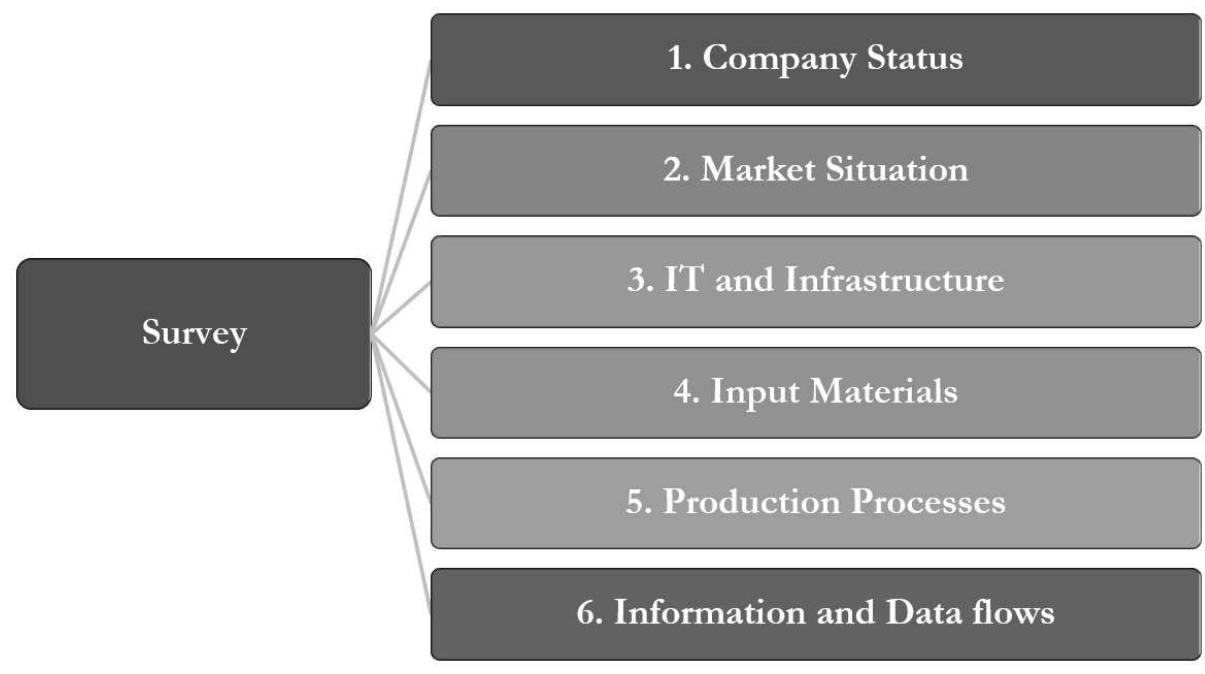

Fig. 3 Design of the Industry 4.0 Readiness Model for the refractory industry

\begin{tabular}{|c|c|c|}
\hline \multicolumn{3}{|c|}{ SWOT ANALYSIS } \\
\hline & STRENGHTS & WEAKNESSES \\
\hline$\frac{1}{2}$ & $\begin{array}{l}\text { - Selfassesment } \\
\text { - Model can't be used in any other } \\
\text { branch of industry } \\
\text { - Connection between evaluating and } \\
\text { implementing models }\end{array}$ & $\begin{array}{l}\text { - Digitalization of whole process } \\
\text { - Better source and orders planning } \\
\text { - Model is focused on few primaries } \\
\text { not whole problem } \\
\text { - A need to have an experienced staff }\end{array}$ \\
\hline & OPORTUNITIES & THREATS \\
\hline 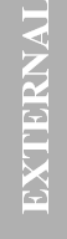 & $\begin{array}{l}\text { - Digitalization of whole process } \\
\text { - Better source and orders planning } \\
\text { - Model is aimed only for refractory } \\
\text { - Competitive advantage }\end{array}$ & $\begin{array}{l}\text { - Wrong interpretation of results } \\
\text { - Safety of data } \\
\text { - } \\
\text { Model can't be used in any other } \\
\text { branch of industry }\end{array}$ \\
\hline
\end{tabular}

Fig. 4 SWOT analysis

One of the main strengths of the proposed evaluation model of the company's readiness for the implementation of elements of industry 4.0 is its complexity when used in the refractory. The financial costs of performing the analysis are relatively low, because the analysis is performed by the company itself. Thanks to the interconnection of the evaluation and implementation model, the company can determine for itself in which sector the analysis of readiness and subsequent implementation of elements of industry 4.0 will be performed.

The proposed evaluation model focuses on individual problems and unfortunately doesn't provide a solution to the whole issue. Due to the great complexity of using the evaluation and implementation model, the whole process of evaluation and subsequent implementation of elements of industry 4.0 is very time consuming. At the beginning it is necessary to appoint 
a team of authorized personel who will lead the whole process. If the team is not sufficiently experienced and familiar with the issue, there may be a misunderstanding or non-compliance with the evaluation process.

Based on a relatively extensive examination of the issue, it was concluded that an evaluation model for the introduction of elements of industry 4.0 is still not created, which would be designed especially for refractory. The implementation of IT infrastructure and IoT can provide the company with "data history" that can be used in future research and optimization of production processes. Thanks to the already mentioned IT infrastructure and IoT, the company should be able to maintain its competitiveness and improve its ability to plan orders and used resources.

The proposed evaluation models are designed for use only with refractory, so it would be very difficult to use them in another industry. There is a security risk associated with the introduction of IT technologies and IoT. A company must defend itself against attacks by hackers, because it could lose its know-how and very sensitive data due to data leakage.

\section{- Company Status}

The first step is to evaluation of the current state of the company. Important factor that plays a big role in evaluating readiness for the implementation of elements of Industry 4.0 is to gain an overview of the company's financial situation. The changes associated with the introduction of the elements of Industry 4.0 are in most cases expensive and it is necessary to think about the way of financing and the maximum amount of investment that the company is able to release. The strategy of the company is related to the investment. If a business has no strategy, it will be more difficult for it to prepare for change. A company that has a comprehensive strategy, has an overview of its future direction and can also modify this strategy at any time. No less important factor for the Industry 4.0 elements implementation is the size and the turnover of monitored company. A small company that doesn't have a high turnover should not think of a high investment in the Industry 4.0 elements implementation, while a large company whose turnover is many times higher has greater potential to capitalize on the investment in the implementation of Industry 4.0 elements.

\section{- Market Situation}

The second step in the proposed methodology is to evaluate the market and product development. It is very important to predict how the situation of the market, in that business sector where the company operates, will evolve. If demand for a given product is expected to decrease, it is advisable to think about the development of the production profile or its complete change. In addition to future development, it is also important to evaluate the current state of the market, its possibilities and the position of the company in the market.

\section{- IT and Infrastructure}

This category solves the current culture and state of the company in terms of IT and infrastructure. The current state of networking in the company are gradually being solved and if the machines are connected by hardware or if they are connected wirelessly. Other thing which is being solved is Wi-Fi coverage in whole company. Whether they are able to retrieve data with the machines. Next step is to define how they work with the data in the current situation and if they can use it for back analysis. Simultaneously, software security (ERP, PLC, MES, CAD, etc.), production planning process, number and qualification of IT staff are being solved in the same time. It is also necessary to find out whether the company uses the cloud or another form of storage to collect and store data. In the context of data sharing it is important to be available throughout the company.

\section{- Input Materials}

Considering to the input materials, it is absolutely crucial to determine the current state of the takeover of materials and their storage. First of all the origin of all raw materials and the possibility of supplying data on their status are ascertained. Some companies in the refractory industry extract all or part of the materials they need while others buy them all. In most cases, the delivered material condition is not documented at the acceptance and it is dependent on the season (especially the humidity). For this reason, it is necessary to identify when the company ascertains the condition of the material. Whether the condition is detected already in the warehouse or during the preparation of the mixture, where depending on the state of the material the recipe and the amount of added water is adapted. The current conditions in the warehouse, warehouse equipment using sensors, the possibility of data collection and their digitization are analyzed. At the same time, recycling of own raw materials and ground scrap products is being solved in this category.

\section{- Production processes}

The production processes are focused purely on the technology of the production system. In the first part the questions are focused on the preparation of the mixture. It is being determined if the tools are equipped with humidity sensors, the type of raw material transport to the mixer and its automatic filling. In case of using the obtained data, their analysis and reuse, it is necessary to find out whether the data is used for automatic filling of stabilizers, water and the complete composition of the recipe mixture adjusted according to the data. In the molding section, the tools are equipped with pressure sensors on presses, production time and the type of the used technology (some technologies may be worse or not equipped with sensors). It is also essential to find out whether a 
system of mold digitization and wear monitoring is used. The shaped articles are dried and burned in respective kilns on kiln cars. During these operations, the kiln operation time is determined by which the temperature is adjusted, thereby influencing and controlling the residual moisture and whether the sensor data obtained actively affects the change in the actual furnace conditions. The last important part in terms of production processes is quality control. In some companies, this activity is being made manually and measurement evaluation is done by qualify workers. On the other hand, in some companies the quality control is fully automated data can be obtained and flawlessly distinguish between compliant and noncompliant products. At the same time, the obtained data can be used retrospectively to improve the production process. The aim is to determine the current status of quality control.

- Information and Data flow

The last category is Information and data flows in the company, mainly focused on state of processes in the company. In this category, it is determined whether data collection works using the sensors, IT equipment and infrastructure for vertical and horizontal communication within the machine. Whether the acquired data is sent to a central system that selects the data and sends it to the appropriate machines or uses decentralized control. Whether a machine-to-machine communication exists, or how data sorting and data interconnection with the supplier and customer are

done.

In the model, all categories listed above are evaluated separately and after that, based on the weights of each category, the overall readiness for Industry 4.0 is determined. The distribution into several categories is suitable for the future implementation model which according to the importance and the current state of each category will provide a suitable implementation procedure.

\section{Design of implementation model of ele- ments of Industry 4.0 based on evaluation model}

The proposed Implementation methodology will be based on the methodology for evaluating the Industry 4.0 readiness of the refractory industry described in this article. The methodology will include 3 stages of the procedure. In the first phase, the most critical sites that need to be addressed primarily will be identified based on readiness assessments. This phase will also include an evaluation of these bottlenecks according to their importance to the refractory industry. The second phase will be the creation of a strategic plan for the implementation of Industry 4.0 elements, staff training and others. Then comes the third phase of actual implementation of the selected elements, according to the strategic plan. Readiness evaluation follows again. This process will be then repeated until the desired state is reached (see 5).
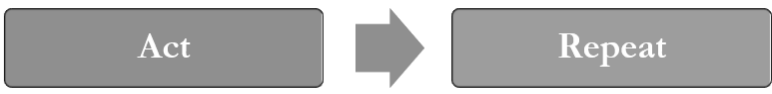

Fig. 5 Projects within Industry 4.0 in Ceramics industry

\section{Conclusion}

This article presents the results of a study that focuses on designing a readiness model for evaluating a company in the refractory industry to implement Industry 4.0 elements. There are several companies around the world that have been dealing with this issue for several years, but most of the models developed focus on the automotive or aerospace industry, not the refractory industry. Evaluation models are mostly based on the questionnaire principle and subsequent evaluation of the current status. Unlike the automotive industry, the implementation of Industry 4.0 elements in the refractory industry is very difficult because some businesses still use outdated technology and almost do not use data digitization, also there are more strict conditions for the production itself, apart from other subsectors of ceramic industry.

In the second part, a readiness model was designed to evaluate the current state of readiness of the monitored enterprise for the implementation of Industry 4.0 elements. In this model there are 6 groups in which the current state of the company is analyzed in detail. The proposed methodology for evaluating the company's preparedness for Industry 4.0 will subsequently be paired with the Model for the implementation of elements of Industry 4.0. This model for the implementation process is still in development, preliminarily divided into 4 basic phases (see 5). These phases are repeated until the desired results are achieved, giving accurate results that can be used to increase productivity and quality of the entire production. By the combination of Readiness model described in this article and future Model for the implementation of elements of Industry 4.0 to Refractory Industry, new tool for complex and precise assessment and implementation of modern solutions for Refractory companies will be developed.

\section{Acknowledgement}

This work was supported by the Czech Technical University and funded from Student grant competition - grant number SGS19/105/OHK2/2T/12 


\section{References}

[1] LANG, K. (2010). Refractory materials. Prague. CSVTS - Silicate Company of the Czech Republic (Silikátová společnost České republiky), 2010.

[2] KELLNER, T., M. KYNCL, J. KYNCL, M. KOPTIS, J. URBAN, L. BERANEK a M. KOTOUSEK. (2019). Manipulation with Raw Ceramic Chimney Pipes. Manufacturing Technology. 2019, (3). ISSN 1213-2489.

[3] KYNCL, J., T. KELLNER, R. KUBIS. (2017). Tricanter production process optimization by digital factory simulation tools. $M a$ nufacturing Technology. 2017, (17). ISSN 12132489.

[4] BARATA, J. SILVA, F. a ALMEIDA, M. (2019). Ceramic Industry 4.0: Paths of Revolution in Traditional Products. In: Technological Developments in Industry 4.0 for Business Applications. IGI Global, 2019. ISBN: 978-1-5225-4936-9 978-1-5225-4937-6.

[5] Industry 4.0 Self Assessment. PwC [online]. 2016 [quoted 2019-12-18]. Available from: https://i4-0-self-assessment.pwc.nl/i40/landing/

[6] The Connected Enterprise Maturity Model [online]. Rockwell Automation, 2014 [quoted 2019-12-
19]. Available from: https://literature.rockwellautomation.com/idc/groups/literature/documents/wp/cie-wp002_-en-p.pdf

[7] ISAKA, Hideya, Hiroto NAGAYOSHI, Hiroshi YOSHIKAWA, Toshihiro YAMADA a Nobuhiro KAKENO. (2016). Next Generation of Global Production Management Using Sensing and Analysis Technology. : Hitachi Review Vol. 65 (2016), No. 5

[8] Industry 4.0 Readiness Online Self-Check for Businesses. IMPULS [online]. [quoted 201912-19]. Available from: https://www.industrie40-readiness.de/?lang=en

[9] LEYH, C., BLEY, K., SCHÄFFER, T., BAY, L. (2017). The Application of the Maturity Model SIMMI 4.0 in Selected Enterprises: The Application of SIMMI 4.0. Boston, 2017.

[10] SCHUMACHER, A., EROL, S., SIHN, W. (2016). A Maturity Model for Assessing Industry 4.0 Readiness and Maturity of Manufacturing Enterprises. Procedia CIRP. 2016.

[11] GANZARAIN, J., ERRASTI, N. (2016). Three Stage Maturity Model in SME's towards Industry 4.0. Journal of Industrial Engineering and $M a-$ nagement. OmniaScience, 2016. ISSN 20130953. 